\title{
Vibration exposure, smoking, and vascular dysfunction
}

\author{
Martin Cherniack, Jonathon Clive, Adam Seidner
}

\begin{abstract}
Objectives-Vibration white finger (VWF), also known as "occupational Raynaud's phenomenon", is marked by arterial hyperresponsiveness and vasoconstriction during cold stimulation. The impact of tobacco use, and by extension stopping smoking, on the long term course of the disease has been inconclusively characterised. The objectives of this study included assessment of the impact of tobacco use on symptoms and on objective tests in shipyard workers exposed to vibration, and in gauging the natural history of the disorder after stopping exposure and changing smoking patterns.
\end{abstract}

Methods-In a cross sectional investigation, 601 current and former users of pneumatic tools were evaluated subjectively for cold related vascular symptoms, and tested by cold challenge plethysmography. There was follow up and subsequent testing of 199 members of the severely effected subgroup of smokers and non-smokers, many of whom had stopped smoking in the interval between tests. Effects of smoking and stopping smoking on symptoms and plethsymographic results were assessed.

Results-Symptoms and measured abnormal vascular responses related to cold were more severe in smokers than in nonsmokers. Follow up of 199 severely effected members of the cohort, all removed from exposure for 2 years, indicated that smokers were almost twice as likely to have more severe vasospasm (test finger/ control finger systolic blood pressure\% $($ FSBP\%) <30) than were non-smokers $(-32.2 \%$ v $17.4 \%) .53$ Subjects who stopped smoking during the interval between tests improved, and were indistinguishable from non-smokers similarly exposed to vibration. Additional physiological benefits of stopping smoking were still apparent at further follow up examination, 1 year later. Improvements evident on plethysmography were not accompanied by improvements in symptoms, which were unaffected by smoking.

Conclusions-Smoking seems to delay physiological improvement in response to cold challenge in workers with VWF, after the end of exposure to vibration. Symptoms were less likely to improve over time than digital blood pressure, and were less affected by smoking.

(Occup Environ Med 2000;57:341-347)
Keywords: vibration white finger; cold challenge plethysmography; smoking; Raynaud's phenomenon

Vasodilator and vasoconstrictor substancessuch as endothelin relaxing factor (EDRF), free radicals, and endothelin - locally regulate vascular tone in the peripheral vessels. ${ }^{1}$ Cigarette smoking has been strongly associated with a range of dysfunctional endothelial responses, including impaired short and long term vasoconstriction, ${ }^{2}$ an impaired intrinsic vasodilator response, ${ }^{3}$ and abnormal perfusion during cold. ${ }^{4}$

Arterial hyperresponsiveness and impaired vasodilation after cold challenge are also characteristics of vibration white finger (VWF) or "occupational Raynaud's phenomenon", an acquired vasospastic disorder associated with the regular use of hand held pneumatic and oscillating tools. These tools include chainsaws, metal grinders, chipping hammers, and impact wrenches. ${ }^{5-7}$ In some studies, more than $70 \%$ of an exposed workforce will have signs and symptoms of local vasospasm in the fingers, most often measured by recording finger systolic blood pressure and digital temperature stability during cold challenge. ${ }^{8} 9$ Although one main mechanism of vasospasm induced by vibration seems to be attributable to local autonomic dysfunction, ${ }^{10}{ }^{11}$ a more generalised intrinsic vascular pathology may also contribute to hand symptoms and impaired function. Finger biopsies of workers heavily exposed to local vibration have shown signs of considerable endothelial injury. ${ }^{12}{ }^{13}$ Increased formation of free radicals and increased leukotriene B4 concentrations, both indicators of atheromatous injury, are found concommitantly with exposure to vibration. ${ }^{14}$ An overall satisfactory pathophysiological model for occupational Raynaud's phenomenon has been elusive.

An expected additive effect or even interaction of vibration and smoking seems plausible, even probable. However, such evidence has been either modest or contradictory. In studies of vasospastic symptoms,${ }^{15}$ or cold related deficits in finger systolic blood pressure, ${ }^{16}{ }^{17}$ there has been scant measurable difference between smokers and non-smokers. Ekenvall and Lindblad $^{18}$ specifically considered interactions between smoking and exposure to vibration: they found a more abnormal vascular response to cold challenge among smokers when cases were stratified by symptoms. Thus, although some evidence points to a moderate worsening of symptomatic Raynaud's disease when workers exposed to vibration also smoke, because of either small sample size or design limitations of cross sectional studies it has been surprisingly 
difficult to measure an interaction between smoking and vibration.

\section{Subjects and methods}

Between 1988 and 1994, more than 600 shipyard workers were referred to a university medical centre sponsored programme for evaluation of vasospastic disease related to vibration. All subjects were current or former skilled metalworkers from trades with documented use of pneumatic tools that averaged $>10$ hours a week. Vascular assessment included grading clinical symptoms with the Stockholm workshop scale, ${ }^{19}$ completion of a supplemental symptoms questionnaire, and a cold provocation test.

Cooling was produced by circulating water at $15^{\circ} \mathrm{C}$ and $10^{\circ} \mathrm{C}$ through a digit occlusion cuff and the results were normalised to an ambient water temperature $\left(30^{\circ} \mathrm{C}\right)$ and to a non-cooled reference finger. For almost two decades, this technique (cold challenge plethysmography) has been the field and laboratory standard for assessing VWF. ${ }^{8}{ }^{9}$ Results are presented as a proportion (test finger/ control finger) finger systolic blood pressure $\%$ or FSBP $\%$. All FSBP repeated measurements used the same methods and apparatus as the original test (Digimatic 2000, Medimatic, and Copenhagen).

In this study, results are reported for digital cooling at $10^{\circ} \mathrm{C}$. The FSBP $\%$ results were also combined into three aggregates: $<30 \% ; 30$ $59 \%$; and $\geqslant 60 \%$. Other investigators have used these divisions to discriminate between categories of disease and vascular response, and their assumption here is strictly conventional. The FSBP $\%$ cut off of $30 \%$ for the most abnormal results reflects the uncertainty in delineating FSBP measurements $<32 \mathrm{~mm} \mathrm{Hg}$, when venous pressures could mask low pressure arterial flow. The intermediate cut off of $60 \%$, delineating normality from disease, corresponds with other studies, and does not reflect the measured distribution of results in this particular population. Most investigators have found a decided left sided shift to measured FSBP\%. A leading contributor argues that FSBP $<30 \%$ results actually reflect an $\mathrm{FSBP}=0$, there being only two true categories of response, normal and $\mathrm{FSBP}=0 .{ }^{8}$

Concurrently, each subject was also allocated a stage $0-I V$ on the Stockholm workshop scale, a consensus rating system that classifies vibration related vasospasm into progressive symptom categories. ${ }^{19}$ As stage 0 indicates absence of symptoms, and stage IV represents trophic changes, which were not found in this group, essentially all subjects fell into stages I-III. Stage III reflects frequent attacks involving most fingers and extending beyond the proximal phalange. The differentiation between symptoms of stage I and stage II, but not stage III, is potentially ambiguous.

An initial subject file was created and then updated with each subsequent evaluation. This file consisted of current and past occupational history, a symptom severity questionnaire, and a description of past uses of pneumatic tools, involving types of tools, periods of exposure, and estimated years of use. All subjects had completed detailed smoking histories as part of an initial clinical assessment; a contemporaneous smoking history was also obtained at the time of the test. The critical information was current or former smoking and time of last cigarette consumption. Subjects were acclimatised for 1 hour before beginning the testing, which was scheduled in the morning, and before work. An additional hour was required for intake and preparation. Test subjects were instructed not to smoke on the day of the test. If there was acknowledged smoking the morning of the test, the 1 hour abstinence was still observed, but the test result was coded as "just smoked". There was no objective validation by markers of smoking - such as concentrations of cotinine.

There were 208 follow up tests performed a year after the initial test. The planned interval between tests was 12-13 months. Retesting was not, however, mandatory, and was flexible, accommodated around the work schedule during the target retesting window. This was a highly selected retest cohort. Criteria for retesting were earlier test abnormality (FSBP $<70 \%$ ), considerable unabated symptoms (stage III) in the absence of exposure, or stage I symptoms or greater and continued exposure. There was an active intervention programme of redesigning jobs and modifying duties for workers with diagnoses of VWF. At the time of the second test, almost all workers had been removed from their exposures to vibratory tools or were no longer working in a shipyard trade. Of the retested subjects 199 were no longer exposed, and this group served as a natural experiment for assessing the comorbidity and natural history of smoking and VWF, after exposure had stopped. Continued exposure to vibration had been an important confounder in other studies. ${ }^{20}$ In all retested subjects, FSBP\% was measured in the identical finger that was tested in the previous examination. By protocol, this was the most severely effected digit. Also, there were supplemental questions at follow up on change in smoking patterns and changes in symptoms during the interval between tests.

Principal response variables are subjective evaluation of symptoms (the Stockholm scale), $\mathrm{FSBP} \%, \Delta \mathrm{FSBP} \%$ (the difference between tests), $\mathrm{FSBP} \% \geqslant 30$ (the difference between tests for all $\mathrm{FSBP} \%$ results $\geqslant 30$ ), and grouped changes in stage for symptoms and $\mathrm{FSBP} \%$. Independent variables include age, exposureyears, the interval between the last exposure and the test, and smoking. Variability in recollection of tool use excluded indices of exposure that were more detailed than exposure-years. Due in part to an aggressive programme to stop smoking among shipyard workers, particularly those exposed to either asbestos or vibration, there was a considerable proportion of workers who stopped smoking during the interval between tests. After the initial test, this group was treated as a discrete population, distinct from smokers and non-smokers.

Descriptive statistics are expressed as a mean (SEM). Parametric tests were used for all 
Table 1 Characteristics of current smokers and non-smokers, evaluated for arterial vasospasm

\begin{tabular}{|c|c|c|c|c|}
\hline & \multicolumn{2}{|c|}{ Smokers $(n=317)$} & \multicolumn{2}{|c|}{ Non-smokers $(n=284)$} \\
\hline & Mean & SEM & Mean & SEM \\
\hline $\operatorname{Age}^{\star \star}$ & 41.54 & 0.62 & 45.32 & 0.71 \\
\hline Exposure $(y)^{\star}$ & 14.79 & 0.50 & 16.73 & 0.60 \\
\hline \multirow{2}{*}{\multicolumn{5}{|c|}{ Time from last exposure to }} \\
\hline & 19.89 & 1.26 & 27.41 & 1.77 \\
\hline Exposed at time of test (\%) & 14.83 & & 12.32 & \\
\hline FSBP $\% \star \star \star ~$ & 47.43 & 2.12 & 61.20 & 2.24 \\
\hline $\mathrm{FSBP} \%<30^{\star \star}$ & \multicolumn{2}{|c|}{$122 \quad(38.8 \%)$} & \multicolumn{2}{|c|}{$59 \quad(20.8 \%)$} \\
\hline
\end{tabular}

${ }^{\star}<0.05 ;{ }^{\star \star} \mathrm{p}<0.001 ;{ }^{\star \star \star} \mathrm{p}<0.0001$.

Table 2 Smoking and test finger/control finger systolic blood pressure\% $($ FSBP\%)

\begin{tabular}{lcllc}
\hline Smoking & $\begin{array}{l}F S B P \% \\
<30\end{array}$ & $\begin{array}{l}\text { FSBP\% } \\
30-59\end{array}$ & $\begin{array}{l}\text { FSBP\% } \\
\geqslant 60\end{array}$ & \\
\hline Non-smoker & 59 & 35 & 190 & 284 \\
Smoker & 123 & 41 & 153 & 317 \\
Total & 182 & 76 & 343 & 601 \\
Smokers (\%) & 67.6 & 54.0 & 44.6 & 52.8 \\
\hline
\end{tabular}

$\mathrm{p}<0.0001$, by $\chi^{2}$ test.

analyses. The distribution of smokers, former smokers, and non-smokers among the stage categories was analysed by $\chi^{2}$ and by Fisher's exact test. Identification of factors jointly influencing changes in FSBP was evaluated by logistic regression, and by analysis of coviarance (ANCOVA).

\section{Results}

CROSS SECTIONAL RESULTS

There were 601 former or current pneumatic tool users with vasospastic symptoms related to cold who were tested at least once (table 1). There were significant differences between smokers (n-317) and non-smokers $(n=284)$ for essential exposure and demographic variables. Smokers were younger than non-smokers (41.54 v 45.32 years; $\mathrm{p}<0.001)$; on average, they had 2 years less job experience $(\mathrm{p}<0.02)$, although both groups reflected a mature and extensively exposed cohort. For both the smoking and non-smoking groups, under 15\%

Table 3 Smoking and clinical stage: Stockholm workshop scale

\begin{tabular}{lcccc}
\hline Smoking & $\begin{array}{l}\text { Stage 0-1 Minimal } \\
\text { symptoms }\end{array}$ & $\begin{array}{l}\text { Stage II Moderate } \\
\text { symptoms }\end{array}$ & $\begin{array}{l}\text { Stage III Severe } \\
\text { symptoms }\end{array}$ & \\
\hline Non-smoker & 86 & 85 & 113 & 284 \\
Smoker & 74 & 134 & 109 & 317 \\
Total & 160 & 219 & 222 & 601 \\
Smokers (\%) & 46.3 & 61.2 & 49.1 & 52.8
\end{tabular}

$\mathrm{p}=0.007$ by $\chi^{2}$ teat.

Table 4 Characteristics of smokers, non-smokers, and former smokers who had stopped smoking between first test and follow up

\begin{tabular}{|c|c|c|c|c|c|c|}
\hline & \multicolumn{2}{|c|}{ Smoker $n=90$} & \multicolumn{2}{|c|}{ Non-smoker $n=56$} & \multicolumn{2}{|c|}{ Former smoker $n=53$} \\
\hline & Mean & SEM & Mean & SEM & Mean & SEM \\
\hline $\mathrm{Age}^{\star}$ & 39.43 & 1.08 & 45.38 & 1.52 & 44.91 & 1.59 \\
\hline Exposure $(y)^{\star}$ & 13.80 & 0.93 & 17.54 & 1.49 & 17.12 & 1.36 \\
\hline \multicolumn{7}{|l|}{ Time since 1 st test } \\
\hline (months) & 23.15 & 1.65 & 22.84 & 3.13 & 31.20 & 3.22 \\
\hline Interval between tests ${ }^{\star}$ & 12.04 & 0.77 & 11.18 & 0.53 & 14.34 & 0.92 \\
\hline $\mathrm{FSBP}_{\mathrm{BL}} \%$ & 42.84 & 3.98 & 53.84 & 4.38 & 46.24 & 5.86 \\
\hline $\mathrm{FSBP} \%$ * & 53.10 & 4.13 & 64.31 & 4.43 & 67.24 & 5.02 \\
\hline$\Delta \mathrm{FSBP} \%$ & 10.25 & 4.05 & 10.47 & 3.33 & 20.99 & 6.35 \\
\hline FSBP $\%<30^{\star}$ & \multicolumn{2}{|c|}{$29 \quad(32.2 \%)$} & \multicolumn{2}{|c|}{$10 \quad(17.9 \%)$} & \multicolumn{2}{|c|}{$9 \quad(17.0 \%)$} \\
\hline $\mathrm{FSBP} \% \geqslant 30$ & 78.34 & 2.10 & 78.29 & 2.21 & 80.99 & 2.84 \\
\hline
\end{tabular}

${ }^{\star} \mathrm{p}<0.05$.

$\mathrm{FSBP} \%_{\mathrm{BL}}$ is the $\mathrm{FSBP} \%$ at baseline. were still exposed to pneumatic tools at the time of initial testing; the proportion still exposed to vibratory tools at work was slightly but insignificantly higher among smokers. Overall, the interval between final exposure and testing was more prolonged for nonsmokers than for smokers (27.41 $v 19.89$ months). The FSBP\% was significantly reduced in smokers compared with non-smokers (FSBP\% 47.43 v 61.20; p<0.0001). The bulk of the difference in mean $\mathrm{FSBP} \%$ and the most significant distinction between the two groups is attributable to the higher percentage of smokers with non-detectable FSBP $\%<30 \%$ $(38.8 \%$ v $20.8 \% ; \mathrm{p}<0.001)$. This extensive left skewing for both smokers and non-smokers also accounts for the large variance in $\mathrm{FSBP} \%$.

In table 2 smokers and non-smokers are divided into the three designated FSBP\% categories; in table 3, they are divided into the three categorical stages of the Stockholm workshop scale (0-I, II, and III). In both tables, smokers and non-smokers are distributed disproportionately between the three groups $(\mathrm{p}<0.01)$. In table 2 , the proportion of non-smokers increased as $\mathrm{FSBP} \%$ rose. In table 3, there was no association between symptoms and smoking; the higher proportion of smokers with stage II symptoms accounts for the differences between groups.

LONGITUDINAL RESULTS

In table 4, retested smokers and non-smokers are compared. The 109 non-smokers included two distinct subgroups: 56 participants who had not been smoking at the time of their first test and 53 who had discontinued smoking during the interval between tests (14.34 months). Because the invitation to retest was predicated on greater relative abnormality on baseline testing, the initial mean $\mathrm{FSBP} \%$ in retested subjects had been lower than for the entire tested cohort of 601 subjects.

The age and work durations of the two groups of non-smokers were generally similar and were distinct from continuous smokers by greater age and longer duration of exposure $(p<0.05)$. Smokers who successfully stopped smoking during the period between tests had stopped using pneumatic tools for longer (45.54 months) than had smokers (35.09 months) or continuous non-smokers (34.02 months). These converted smokers actually had a lower initial $\mathrm{FSBP} \%$ at initial testing than non-smokers (46.24\% v 53.10\%), despite their longer period away from tools; and they had an even greater interval improvement in their FSBP\% (20.99\% $v 10.47 \%)$ than continuous non-smokers. Most of this comparative improvement can be accounted for by the lower baseline $\mathrm{FSBP} \%$ of converted smokers, as on retest non-smokers and converted smokers had become almost identical populations in their pattern of vascular response. The critical difference between the smoking and nonsmoking groups was attributable to the proportionately larger number of smokers whose FSBP \% remained below the detectable threshold $(32.2 \%$ of smokers and $17.4 \%$ of nonsmokers). When all stage I tests were removed, 
the FSBP\% was virtually identical for smokers and non-smokers. Continuing smokers were a distinctly different population and account entirely for the variation between groups in vascular response.

A more general presentation of the distribution of improved change in FSBP\% was accessible by grouping data. In table 5 , movement between values of $\mathrm{FSBP} \%$ was assessed as either improvement or stabilisation, or morbidity or deterioration. For the worst initial value (FSBP\% <30), improvement or stabilisation was recorded as progression to $\mathrm{FSBP} \% \geqslant 30$ and morbidity or deterioration was recorded if FSBP $\%<30$ persisted. For an initial value of FSBP $\%$ of 30-59, improvement or stabilisation was recorded if the case progressed to FSBP\% $\geqslant 60$ or stayed at FSBP\% 30-59, and morbidity or deterioration was recorded if there was deterioration to $\mathrm{FSBP} \%<30$. For an initial value of $\mathrm{FSBP} \% \geqslant 60$, improvement or stability was recorded if that value persisted, and morbidity or deterioration meant that there was a deterioration to FSBP $\%<60$. From this perspective, smokers were almost twice as likely to deteriorate or remain in a morbid state than were non-smokers and former smokers $(37.8 \%$ v $20.1 \%(\mathrm{p}<0.02))$.

A different situation arose when subjectively derived symptom stage (Stockholm workshop scale) is the outcome of interest. Table 6 shows

Table 5 Improvement or stability $v$ continued morbidity in smokers and non-smokers as indicated by distribution of change in FSBP\%

\begin{tabular}{lclrl}
\hline & $\begin{array}{l}\text { Improved or } \\
\text { stabilised } n(\%)\end{array}$ & $\begin{array}{l}\text { Morbid or } \\
\text { deteriorated } n(\%)\end{array}$ & Total & \\
\hline Smoker & $56(62.2)$ & $34(37.8)$ & 90 & \\
Non-smoker & $45(80.4)$ & $11(19.6)$ & 56 & \\
Former smoker & $42(79.2)$ & $11(20.8)$ & 53 & $(100)$ \\
Total & $143(71.8)$ & $56(28.2)$ & 199 & \\
\hline
\end{tabular}

$\mathrm{p}<0.02$ by $\chi^{2}$ test.

Table 6 Stockholm workshop scale symptoms: improvement or stability v continued morbidity in smokers and non-smokers

\begin{tabular}{lclrl}
\hline Status & $\begin{array}{l}\text { Improved or } \\
\text { stabilised } n(\%)\end{array}$ & $\begin{array}{l}\text { Morbid or } \\
\text { deteriorated } n(\%)\end{array}$ & Total & \\
\hline Smoker & $56(62.2)$ & $34(37.8)$ & 90 & \\
Non-smoker & $36(64.3)$ & $20(35.7)$ & 56 & \\
Former smoker & $36(67.9)$ & $17(32.1)$ & 53 & $(100)$ \\
Total & $128(64.3)$ & $71(35.7)$ & 199 & $(10)$ \\
\hline
\end{tabular}

$\mathrm{p}=0.848$ by $\chi^{2}$ test.

Table 7 Characteristics of smokers, non-smokers, and former smokers who stopped between 2nd and $3 r d$ tests

\begin{tabular}{|c|c|c|c|c|c|c|}
\hline & \multicolumn{2}{|c|}{$\begin{array}{l}\text { Smoker } \\
n=35\end{array}$} & \multicolumn{2}{|c|}{$\begin{array}{l}\text { Non-smoker } \\
n=39\end{array}$} & \multicolumn{2}{|c|}{$\begin{array}{l}\text { Stopped smoking } \\
n=15\end{array}$} \\
\hline & Mean & SEM & Mean & SEM & Mean & SEM \\
\hline Age & 41.40 & 1.76 & 44.67 & 2.06 & 43.33 & 2.76 \\
\hline Exposure (y) & 13.37 & 1.21 & 16.56 & 1.47 & 16.93 & 2.68 \\
\hline Time from 1 st to 2 nd & 31.52 & 3.62 & 33.28 & 4.97 & 30.88 & 4.66 \\
\hline \multicolumn{7}{|l|}{ Interval between $2 \mathrm{nd}$} \\
\hline $\mathrm{FSBP} \%_{\mathrm{BL}}$ & 35.04 & 6.51 & 40.86 & 6.21 & 38.07 & 10.24 \\
\hline$\Delta \mathrm{FSBP}_{\mathrm{BL}-\mathrm{FT}} \%$ & 14.37 & 5.77 & 32.91 & 6.45 & 25.04 & 12.59 \\
\hline 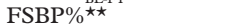 & 49.24 & 6.30 & 73.76 & 4.15 & 63.11 & 10.29 \\
\hline$\Delta \mathrm{FSBP} \%$ & 10.69 & 5.01 & 5.98 & 6.24 & 18.07 & 7.57 \\
\hline FSBP $\%<30$ & \multicolumn{2}{|c|}{$17 \quad(48.58 \%)$} & \multicolumn{2}{|c|}{$6 \quad(15.38 \%)$} & \multicolumn{2}{|c|}{$5 \quad(33.33 \%)$} \\
\hline $\mathrm{FSBP} \% \geqslant 30^{\star}$ & 78.67 & 3.47 & 71.66 & 3.76 & 74.59 & 6.23 \\
\hline
\end{tabular}

$\mathrm{FSBP} \%{ }_{\mathrm{BL}}$ is the $\mathrm{FSBP} \%$ at baseline.

$\triangle \mathrm{FSBP}_{\mathrm{BLT}}$ is the change in FSBP from the baseline test to the third test.

$\mathrm{FSBP} \%$ and $\triangle \mathrm{FSBP} \%$ refer to the third test and the change from the second to the third test.

${ }^{\star} \mathrm{p}<0.05 ;{ }^{\star \star} \mathrm{p}<0.005$ by Fisher's exact test. morbidity and improvement in these more qualitative terms. For stage III subjects (most severe), stability or improvement was indicated if there was improvement to stage II or I and morbidity or deterioration meant that the subject remained at stage III. For stage II subjects, stability or improvement meant that there was improvement to stage I or no stage change, whereas morbidity or deterioration meant deterioration to stage III. For stage I subjects, stability or improvement meant maintenance in stage I or in stage II, whereas morbidity or deterioration was a decline to stage III. The delineations are conservative, reflecting potential subjective unreliability in differentiating between stage I and II. There was no significant difference between smokers and the two non-smoking groups in the magnitude of symptom change. Where follow up of workers with VWF was attempted, deliberate intervention and unforeseen drop out sometimes resulted in sizable variation in between test intervals and in sporadic compliance from the original cohort. Self selection and alteration of work processes, including job rotation or elimination, substitution of antivibration tools, and medical removal from exposure were all mitigating factors. Results from a third testing interval, more extended in time and potentially reflective of some of these selection factors, are reported in table 7 . This was a third annual follow up test so that mean latencies between last exposure and this test range from 40.94 months for smokers to 42.98 months for former smokers. Because earlier abnormal tests or unimproved moderate or severe symptoms were the requisite retest criteria, medical selection played an important part. The criteria for ending the testing in subjects with previously abnormal FSBP $\%$ was an $\mathrm{FSBP} \%>70$ or two annual measurements $>60 \%$. Again, the influence of an aggressive programme to stop smoking can be appreciated as an additional $17.0 \%$ of the retested smokers had stopped smoking in the interval between tests. The non-smokers approached normality as a group and experienced the least improvement of the three subpopulations (mean $\triangle \mathrm{FSBP} \% 5.98$ ). The continuing smokers with multiple tests had a more substantial relative improvement (mean $\triangle \mathrm{FSBP} \% 10.69$ ). If this were the only available follow up data, and there was no separation of recent former smokers, then smoker and non-smoker groups would be more similar in size (35 smokers and 54 nonsmokers) and the FSBP\% 9.34 for nonsmokers would have suggested that there was relatively less improvement than the smoking group experienced, although the mean FSBP\% was considerably higher. The reality was different. The continuous non-smokers had an improvement in $\mathrm{FSBP} \%$ of 32.91 between the initial and third tests; whereas the improvement in continuous non-smokers was 14.37 over the same interval. Smokers seemed to experience a delay in recovery but the effects of stopping smoking continued to be dramatic almost 3 years after the last exposure.

A logistic regression analysis was run with the dependent variable being improvement or 
morbidity in the $\mathrm{FSBP} \%$ between the first and second tests, with the same staging criteria used in table 6. Continuous independent variables were age, work duration, $\mathrm{FSBP} \%$ at the first test, and latency to test. Smoking was grouped. The only variables that showed significance when the other variables were taken into account was initial $\mathrm{FSBP} \%$ and current smoking at the time of the second test. Every $10 \%$ deficit in FSBP at the initial test conferred a $2.7 \%$ risk of continued morbidity at retesting. When compared with the group that stopped smoking, continuous smokers had a $44 \%$ greater risk of continued morbidity at retesting. An interaction term for smoking and duration since exposure to vibration was added to the model. There was modest interaction due to a substantial difference in latency between the improvement or stability outcomes in the non-smoking (shorter) and ex-smoking (longer) subgroups. Given the homogeneity of the response pattern, this would seem to lack biological significance.

Several variables were considered as covariates in an analysis of $\mathrm{FSBP} \%$ at the second test, broken down by smoking group. Age, latency, interval between tests, interaction between latency and smoking, exposure, and $\mathrm{FSBP} \%$ at the initial test were examined. Only FSBP $\%$ at the initial test was a viable covariate. An ANCOVA with FSBP\% at the initial test as the only covariate, $\mathrm{FSBP} \%$ at the second test as the outcome measure, and smoking as the grouping variable indicated that initial $\mathrm{FSBP} \%$ accounted for most of the change in FSBP\% and smoking was marginally significant $(p=0.07)$. When analysis was restricted to the FSBP $\% \geqslant 30$ group, the effect of smoking was not significant.

\section{Discussion}

To our knowledge, this is the largest reported group of subjects with occupational Raynaud's disease $(n=601)$ in which vasospasm related to cold has been measured. It also seemed to be the largest group $(n=199)$ with follow up tests after a known end to exposure, making recovery assessable. Obvious strong structural and self selection factors that influenced retesting protocols were generally conservative, working against the follow up of milder cases. Retesting was voluntary, so other than severity of symptoms, there was little that might make smokers who used pneumatic tools want to be included in the study. The young age and shorter work duration of tested smokers compared with non-smokers, suggests that severity of symptoms drove the smokers to both seek medical evaluation and nonscheduled end of work. Despite considerable avenues for self selection, particularly for retesting, our results may resolve some ambiguities in the relation between provoked VWF and smoking.

An assembly bias is certainly possible. It would entail the exclusion of non-smokers with the most abnormal plethysmographic findings. It is unclear how an assembly bias might prevail, as abnormal testing was a criterion for follow up requested by a physician, and self selection would rely on presentation of symp- toms. This was not strongly associated with plethysmographic results. Unfortunately, the cohort has since disbanded, and there is no ready confirmation by direct follow up.

At the time of initial testing, non-smokers had less abnormality in test results than smokers, not an unanticipated finding, in the light of previous reports on the influence of smoking on VWF. Three years after exposure, provoked vasospasm was substantially reduced in nonsmokers, and changed much less markedly in continuing smokers. Vascular responses in smokers who had recently stopped smoking resembled non-smokers. No published account suggests such a rapid improvement in arterial function measured by plethsmography for non-smokers after removal from exposure, or suggests such a dramatic ameliorative effect of stopping smoking.

Ekenvall and Lindblad ${ }^{11}$ studied cross sectional smoking patterns in 245 workers exposed to vibration. Subjects were symptomatically staged and also underwent similar cold challenge plethysmography tests. The principle dependent variable (symptom stage), allows strict comparison with the present study. There were significant, but comparatively modest, differences in $\mathrm{FSBP} \%$ between smokers and non-smokers for each symptom stage. Ekenvall and Carlsson ${ }^{16}$ reported on the follow up of 43 of 68 subjects, originally studied with cold challenge plethysmography. The interval between tests was 3.5-6.0 years. The $\Delta$ FSBP\% was not significantly different between smokers and non-smokers; nor was there an effect of stopping smoking. Peterson et $a l^{21}$ restudied 102 subjects from an original cohort of 132 who had baseline cold challenge plethysmography and Stockholm scale symptom staging. The retesting interval was heterogeneous, ranging from 1-13 years, and there was continued exposure to vibration during the interval between tests. Smokers were more symptomatic than non-smokers, but smoking in the 2 years before retesting had no effect on the FSBP \%. Brubaker et al $l^{15}$ evaluated 146 forestry workers by questionnaire. Smoking patterns did not differ between groups with different symptom.

How are these modest influences of tobacco on VWF reconcilable with the strong effect on initial presentation and on recovery in our cohort of shipyard workers? The size of our study, the uniformity of the testing interval, and the abolition of continued exposure as a confounding variable, give relative weight to the current work. Only the study of Peterson et $a l^{21}$ is truly a follow up study, but the cohort is considerably smaller. Could surreptitious smoking before the test explain the results? There were 19 subjects who admitted smoking in the morning before their initial test, despite instructions. Their mean $\mathrm{FSBP} \%$ was $7.7 \%$ lower than the smokers who denied that they had used tobacco before testing. Accordingly, the 2 hour abstinence before the test did not negate acute effects of tobacco. However, even an additional $10 \%$ unrecognised surreptitious smoking before the test would not substantially alter results. Moreover, the crucial distinction 
between this and the previous studies is the degree of recovery in non-smokers, rather than abnormal responses in smokers.

The FSBP\% seems to be an all or nothing indicator. Once there is a recordable FSBP $\geqslant 30 \%$, improvements are modest and they do not vary significantly with smoking. The main contribution to group morbidity comes from an FSBP $<30 \%$, which occurs substantially more often among smokers and declines when smoking stops. By contrast, recall of symptoms in both the baseline (tables 2 and 3) and restudied cohorts (table 6) suggests only a marginal difference in response between smokers and non-smokers. Stopping smoking also had limited impact on improvement in stage of symptoms. Accordingly, these results do not diverge from earlier reports on symptoms related to smoking that relied on recollection of symptoms as the primary indicator of disease. The results are distinctive, if somewhat surprising: (a) non-smokers had better profiles of vascular function than smokers when exposure to vibration was recent; $(b)$ there was improvement on plethsymography when exposure ended; (c) these advantages are conferred rapidly to smokers who stop; (d) the FSBP\% at retesting was strongly associated with the $\mathrm{FSBP} \%$ measured at initial testing, and (e) smoking patterns, ending exposure, or plethysmographic improvement in $\mathrm{FSBP} \%$ do not much alleviate symptoms. This point requires additional explanation. As diminished symptoms were one of the criteria used to discontinue repeat testing, there is a serial decanting of the least symptomatic cases, so the absence of improvement of symptoms cannot be concluded in the larger cohort of pneumatic tools users who have discontinued exposure. Inception to initial testing is most likely driven by particularly severe symptoms, and natural regression to a less acute state (regression to the mean) would tend to be blunted by the selection criteria for retesting.

The powerful effects of selective loss to follow up and variable testing intervals in so dynamic an occupational disease are captured in table 7 . The reduced size of this follow up group and longer interval between tests made our study more similar in size and circumstance to the cohorts studied by Peterson $e t a l^{1}$ and by Ekenvall and Carlson. ${ }^{16}$ Because there were design factors as well as self selection against retesting of less symptomatic diseases, the overall trend is towards the selection of the most chronic cases among smokers and non-smokers. Fully $26 \%$ of the retested cohort had stopped smoking after their initial test, and another $31 \%$ of the smokers undergoing a third test, also reported that they had stopped smoking in the interval between tests. Less than $10 \%$ of the cohort restudied by Ekenvall and Carlson had stopped smoking between initial and follow up testing. It is certainly possible that the subgroup that is responsive to an aggressive programme to stop smoking differs in other therapeutically favourable ways from the group that continue to smoke. One consequence of the eventual normalisation of plethysmographic response in former smokers is the clearer demarcation of a residual subset of chronic cases with scant evidence of recovery, whose continuing vascular reactivity is no longer masked by smokers with a greater potential for recuperation. This finding is consistent with the findings listed in table 7 .

It seems that amelioration of symptoms does not correspond particularly well to improvement in cold challenge plethsymography, a test that has become something of a gold standard for this disease. A corollary question is whether the evidence of dramatic recovery, particularly in the absence of smoking, is actually an attenuation of disease, or the idiosyncrasy of a device, representative of a clinical result. Does smoking simply depress a measurement of recovery that lacks clinical consequence, or does it retard and truncate a therapeutic response to the end of exposure? Other investigators have found the discordance between FSBP induced by cooling and severity of symptoms. ${ }^{2122}$ The apparent chronicity of vasospastic symptoms has led some authors to conclude that advanced symptomatic disease does not abate after the end of exposure. ${ }^{23}$ The current follow up results support this prognostic pessimism, and lead to the conclusion that stopping smoking only modestly reduces symptoms. Once again, however, the selection of more severe cases for additional testing weakens any inferences from this finding. For now, in assessing effects on VWF of smoking, inferences should be drawn from the specific outcome measures-clinical symptoms or vascular cold challenge testing.

The proposition that continued smoking after the end of exposure to vibration aggravates and prolongs pathological arterial hyperresponsiveness is supported by this evidence. In making this observation, it should also be noted that a low $\mathrm{FSBP} \%$ on initial testing independently predicted a low $\mathrm{FSBP} \%$ on retesting a year later. Whether smokers would approach the measure of response found in non-smokers after several additional years of follow up cannot be concluded from our data. The mechanism through which exposure to vibration and use of tobacco may interact is not known, but there are several findings that suggest a mechanism and pathways for further investigation. Arneklo-Nobin et $a l^{4}$ found that smokers with symptomatic Raynaud's disease induced by vibration and comparably exposed and symptomatic non-smokers both experienced a significant drop in $\mathrm{FSBP} \%$ on cold challenge. The mechanism differed: smokers had both an arterial vasoconstrictor and peripheral cutaneous response; non-smokers only had reduction in skin circulation; and controls had neither, regardless of whether they smoked or not. The particular combination of smoking and exposures to vibration seems to exaggerate cold reactivity in a specific pattern. Patients with primary or secondary Raynaud's disease who do not smoke lack an identifiable hyperresponsiveness to nicotine, ${ }^{25}$ and regular smoking aggravates, but is not causative of primary Raynaud's disease. ${ }^{26}$ Workers in cryosectioning laboratories, habitually exposed to unprotected severe cold and who regularly 
smoked tobacco, did not have increased evidence of Raynaud's disease. ${ }^{27}$ Platelet activation has been found in smokers and thromboxane A2 is a potent vasoconstrictor implicated in vasoreactivity, ${ }^{128}$ but occupational Raynaud's disease does not seem to intensify these mechanisms of vasoconstriction. ${ }^{29}$

The predominant effect of smoking on arterial function is likely to reflect endothelial dysfunction, seems to be endothelium dependent, is impaired with smoking, and is probably reversible with stopping smoking. ${ }^{230}$ Forearm occlusion plethysmography has shown impaired endothelium dependent, but not endothelium independent, vasodilation in smokers. $^{31}$ Retardation of improvement in cold challenged smokers is consistent with many of these findings. The dramatic improvements among non-smokers in this study on cold challenge plethysmography, a test of arterial responsiveness, mirrors the recovered endothelium induced vasodilation found in the coronary and forearm arteries of former smokers. ${ }^{32}$ If VWF in the absence of smoking primarily reflects impaired sympathetic tone, ${ }^{33}$ inhibition of cutaneous flow may involve a mechanism distinct from arterial vasoconstriction.

Any optimism, evoked by the overall favourable course of vascular function on plethsymography and on the therapeutic benefit of stopping smoking, should be tempered by other evidence indicating chronicity in a substantial population of smokers and nonsmokers. At the time of initial testing, which was on average 2 years after the last exposure to pneumatic tools, fully $42.6 \%$ had abnormal tests (FSBP <60), and $72.4 \%$ of the group were classified as stage II or III on the Stockholm workshop scale. Two years later, $32.8 \%$ of the retested subjects had a nondetectable abnormality in FSBP.

A combination of impaired endothelium mediated vasodilatation and impaired local vasoconstriction accords with the results cited in this study and with the finding that over time cold challenge plethysmography underrepresents morbidity that is captured as staged symptoms. ${ }^{22}$ Thus, the most accepted and reproducible test of occupational Raynaud's disease may best record impaired arterial dilatation in smokers and in incumbent or recently exposed workers who used vibratory tools. On the other hand the clinical pattern of cold hyperresponsiveness in both smokers and nonsmokers that seems to persist for many years after exposure has ended may not be amenable to this benchmark test. The application of newer and more sensitive methods to assess cutaneous flow may offer a fuller perspective on chronic disease, and perhaps, on its earliest manifestations. Severity and resistance to recovery may also be consequences of altered physiology rather than indices of prolonged exposure, only.

1 Heitzer T, Seppo Y-H, Luoma J, et al. Cigarette smoking potentiates endothelial dysfunction of forearm resistance vessels in patients with hypercholesterolemia. Circulation 1996;93:346-53. 2 Rigott NA, Pasternak RC. Cigarette smoking and coronary
heart disease. Cardiol Clin 1996;14:51-68.

3 McVeigh GE, Lemay L, Morgan D, et al. Effects of long-term cigarette smoking on endothelium-dependent response in humans. Am F Cardiol 1996;78:668-72.

4 Meeder JG, Blanksma PK, van der Wall EE, et al. Long-term cigarette smoking is associated with increased myocardial perfusion heterogeneity assessed by position emission tomography. Eur f Nucl Med 1996;23:1442-7.

5 Gemne G. Diagnostics of hand-arm system disorders in workers who use vibrating tools. Occup Environ Med 1997; 54:90-5.

6 Pyykkö I. Clinical aspects of the hand-arm vibration system: a review. Scand $\mathcal{F}$ Work Environ Health 1986;12:439-47.

7 Olsen N, Nielsen SL. Diagnosis of Raynaud's phenomenon in quarry-men's traumatic vasospastic disease. Scand $\mathcal{f}$ in quarry-men's traumatic vasospastic

8 Nielsen SL. Raynaud's phenomenon and finger systolic blood pressure during cooling. Scand f Clin Lab Invest 1980;38:765-70.

9 Bovenzi M. Digital arterial responsiveness to cold in healthy men, vibration white finger and primary Raynaud's phenomenon. Scand F Work Environ Health 1993;19:271-6.

10 Gemne G. Pathophysiology of white fingers in workers using hand-held vibrating tools. Nagoya f Med Sci 1994; 57(suppl):87-97.

11 Ekenvall L, Lindblad LE. Is vibration white finger a primary sympathetic nerve injury? $\mathrm{Br} \mathcal{F}$ Ind Med 1986;43:702-6.

12 Takeuchi T, Imanishi H. Histopathologic obsevations in finger biopsy from thirty patients with Raynaud's phenomenon of occupational origin. Fournal of the Kumamoto Medical Society 1984;58:56-70.

13 Takeuchi $T$, Futatsuka $M$, Imanishi $H$, et al. Pathologic changes observed in the finger biopsy of patients with vibration-induced white finger. Scand $f$ Work Environ Health 1985;12:280-3.

14 Lau CS, O'Dowd A, Belch JJF. White blood cell activation in Raynaud's phenomenon of systemic sclerosis and vibration induced white finger syndrome. Ann Rheum Dis 1992; 51:249-52.

15 Brubaker RL, Mackenzie JG, Eng PR, et al. Vibration white fingers disease among tree fellers in British Columbia. $\mathcal{F}$ Occup Med 1983;25:403-8.

16 Ekenvall L, Carlsson A. Vibration white finger: a follow up study. Br f Ind Med 1987;44:476-8.

17 Bovenzi M. Vibration white finger, digital blood pressure, and some biochemical findings on workers operating Ind Med 1988;14:578-84.

18 Ekenvall, L, Lindblad LE. Effects of tobacco use on vibration white finger disease. F Occup Med 1989;31:13-6.

19 Gemne G, Pyykko I, Taylor W, et al. The Stockholm workshop scale for the classification of cold-induced Raynaud's phenomenon in the hand-arm vibration syndrome (revision of the Taylor-Pelmear scale). Scand $\mathcal{F}$ Work Environ Health $1987 ; \mathbf{1 3}: 275-8$

20 Ostman F, Lundboerg G, Bornmyr S, et al. Is vibrationinduced white finger a reversible syndrome if vibration is stopped? F Hand Surg $(\mathrm{Br})$ 1996;21:750-2.

21 Petersen R, Andersen M, Mikkelsen S, et al. Prognosis of vibration induced white finger: a follow up study. Occup Environ Med 1995;52:110-5.

22 Olsen N, Nielsen SL. Vasoconstrictor response to cold in forestry workers: a prospective study. $\mathrm{Br} f$ Ind $\mathrm{Med}$ 1988;45:39-42.

23 Futatsuka M, Ueno T, Sakurai T. Follow up study of vibration induced white finger in chain saw operators. $\mathrm{Br} \mathcal{F}$ Ind Med 1985;42:267-71.

24 Arneklo-Nobin B, Johansen K, Sjoberg T. The objective diagnosis of vibration-induced vascular injury. Scand 7 Work Environ Health 1987;13:337-42.

25 Goodfield MJ, Hume A, Rowell NR. The acute effects of cigarette smoking on cutaneous blood flow in smoking and non-smoking subjects with and without Raynaud's phenomenon. Brf Rheumatol 1996;29:89-91.

26 Planchon B, Pistorius MA, Beurrier P, et al. Primary Raynaud's phenomenon. Age of onset and pathogenesis in a prospective study of 424 patients. Angiology 1994;45: 677-86.

27 Wieslander G, Norback D, Edling C. Local cold exposure of the hands from cryosectioning work in histopathological and toxicological laboratories signs and symptoms of peripheral neuropathy and Raynaud's phenomenon. Occup Environ Med 1996;53:276-80.

28 Nowak J, Murray JJ, Oates JA, et al. Biochemical evidence of chronic abnormality in platelet and vascular function in healthy individuals who smoke cigarettes. Circulation 1987; 76:6-14

29 Nowak J, Barregard L, Benthin G, et al. Thromboxane metabolite excretion in patients with hand-arm vibration syndrome. Clin Physiol 1996;16:361-70.

30 Celermajer DS, Sorense KE, Georgakopoulos D. Cigarette smoking is associated with dose-related and potentially reversible impairment of endothelium-dependent dilatation in healthy young adults. Circulation 1993;88:2149-55.

31 Rangemark C, Wennmalm A. Endothelium-dependent and independent vasocilation and reactive hyperemia in healthy smokers. F Cardiovasc Pharmacol 1992;20:S198-201.

32 Zeihar AM, Schächinger V, Minners J. Long-term cigarette smoking impairs endothelium-dependent coronary arterial vasodilator function. Circulation 1995;92:1094-100.

33 Azuma T, Ohhashi T. Factors modifying the local arterial hyper-responsiveness of vibration-induced white finger. Cardiovasc Res 1983;17:223-8. 